A carriage moving smoothly on four wheels travels beneath the lens at such a distance that the sensitised plate laid upon it comes at the focus for actinic rays. A uniform velocity is given to the carriage by a string fastened to it and passing over a pulley. To this string a lead weight, just sufficient to balance friction, is permanently attached, while a supplemental weight acts at the beginning of motion and is removed just before the sensitised plate reaches the spot of light above described.

The velocity attained by the carriage is determined by placing a sheet of smoked glass upon it and letting it run under a tuningfork (Ut! $3-512 \mathrm{v}$. s.) provided with a pointed wire. In every case more than 200 vibrations were counted and measured, and eareful comparisons made between the earlier and later ones, so as to be certain of the uniformity of the motion.

From the description it will be evident that when the carringe alone is in motion a straight line will be photographed upon the plate. On speaking into the mouthpiece the disc is set in vibration, each movement causing change of angular position of the mirror, the reflected light moves through twice this angle, and the resulting photograph gives us the combination of its motion with that of the carriage. The carriage should run from right to left. The negative (examined from the glass side), and prints taken from it, then give the syilables in their proper order, and show movements of the disc from the speaker by lines going from the observer. The arrangement of my dark room compelled me to make my carriage move from left to right; hence, in the figures given, forward positions of the disc are represented by the lower portions of the curves.

The general character of the curves obtained is shown in the accompanying figures, which are the actual size of the originals, except that representing the vowel-sounds, which is about onehalf $(0.56)$

The velocity of the carriage for the vowel-sounds was $2 \pi \frac{1}{2}$, for Brown University, 40, and for Hoze do you do, 14 inches per second.

In the mathematical discussion of these curves the abscissas are measured by the known velocity of the carriage, and serve to determine the pitch, the ordinates represent the amplitude of vibration of the centre of the disc, magnified 200 times in the photographs. The reduction of scale makes the magnifying in the woodcuts only ri 2 times.

The ordinates are not strictly straight lines, but parts of the vertex of a parabola, and closely approximate to circular arcs whose radius is the focal length of the lens employed. In the figures given, the centres of curvature of these arcs is at the right hand.

With an ordinary tone of voice an amplitude of nearly an inch is obtained, implying a movement of the centre of the disc of .005 inches as determined by actual measurement.

By varying the accelerating weight and its fall, any manageable velocity may be given to the carriage. Each syllable requires for its articulation abont one-fourth of a second, hence the plates must be quite long when the velocity is great. I employ plates two feet in length, and find that velocities from 16 to 40 inches per second give good results. The action of the light is, however, inversely as the velocity. To compensate for this, the size of the circular opening admitting the light may be increased. This, of course, causes an enlargement of the iuminous image, and apparently involves an injurious widening of the line traced, but, as observed by Dr. Stein in his experiments, the effect of velocity is to narrow the line photographed, since the maximum exposure is in that diameter of the circular image which lies in the line of motion. This is a great advan. tage, since a variation of velocity in the vibration is marked by the widening of the line, often more clearly than by the form of the curve.

I have employed the ordinary photographic process, not attempting to obtain special sensitiveness. The brightest sunlight is required, a slight haziness interfering seriously with the result, My heliostat employs two reflectors of ordinary looking. glass, and the loss of light is considerable.

Are all the audible elements of speech traceable in these records? in other words, is the record complete? I am not prepared as yet to answer this question definitely, but the following experiment leads me to doubt whether an affirmative answer can be given, while at the same time it illustrates in a striking manner the sensitiveness of the ear. The mirror was attached to the disk of a receiving telephone and a photograph taken from it while the instrument was talking audibly. The resulting record was almost a smooth line, showing but very slight indications of movement of the mirror. It would there. fore appear that there are distinctly audible elements, which are too minute to be recorded by this method. It is to be noted, however, that the width of the line traced where the vibrations are extremely small, is so great as to mask the curvature, so that the experiment just cited is not entirely fair.

The clearness and beauty of the curves obtained can hardly be appreciated without inspection of the originals. Their complexity and variety open a large field for investigation, and they seem to offer the means of analysis of articulate speech.

\section{THE PHONOGRAPH AND VOWEL SOUNDS} I.-THE VOWEL SOUND O.

IN a recent letter to NATURE we gave a short account of what we believed to be the existing theories of vowel-sounds. In the present paper we will state the chief results as to the vowel $\bar{o}$ of our investigations made by means of the phonograph.

The experiments were made as follows:-The vowel under consideration was spoken or sung at a given pitch, determined by a piano, while the barrel of the phonograph was turned at a definite speed, regulated by means of a metronome. The in dentations made in the tin-foil were then mechanically tran scribed, so as to give curves representing a magnified section of the impressions. The ctrves were magnified by a system of compound levers, and recorded by an arrangement resembling that of Sir William Thomson's siphon-recorder. The details of the apparatus are described in a paper laid by us before the Royal Society of Edinburgh. The vertical ordinates of the curves drawn in ink, as shown below, are about 400 times larger than the corresponding indentations in the tin-foil, while the longitudinal ordinates are multiplied about seven times. The slowness of the motion by which the transcript was made enabled us to avoid all error due to inertia of the working parts, and the total absence of friction between the marking siphon and the paper allowed the transcript to be made without employing such a pressure on the tin-foil as would sensibly alter the indented curves. This fact was in each case tested by making the phonograph speak the vowel after it had been copied. All transcripts were rejected if the tin.foil did not continue to give the sound clearly after being used to produce these curves.

We employed various sizes of chamber and of mouth-piece, various thicknesses of tin-foil, and various discs as receivers. The curves now given as transcripts were found to be practically independent of variations in all these conditions. We are therefore of opinion that the curves do really represent the motion of an air-particle when the vowel is spoken, and that these curves may be regarded as sufficiently unaffected by any periods of vibration proper to the disc and springs employed, or to the air in the chamber of the mouth-piece, to constitute a true record of the essential parts of the vowel-sounds. This may be inferred from the remarkable constancy in the results obtained, with great variations in the conditions of the experiment, and from the fact that the indentations, after beino copied, were in each instance able to give back the vowel-sound distinctly.

Fig. I gives a series of curves produced by a single baritone voice singing $\bar{o}$ on a series of notes ranging from $G$ to $f^{\prime}$. This series has been selected because the voice was of good quality and considerable range.

After the curves were obtained they were subjected to harmonic analysis. One period was divided into twelve equal parts, and twelve ordinates were drawn and measured at right angles to a line joining two successive maximums or minimums. The numbers so determined enabled us to calculate the amplitudes of the first six partial tones.

Table I. gives these amplitudes for the above series of $\bar{o}$ 's, obtained by analysing one period chosen out of the hundreds of similar periods which were given by each utterance. An examination of the curves and of the table will show that the change in character from note to note is fairly gradual and consistent throughout. The figures are arranged so as to show the absolute pitch of each of the six partial tones.

Voices of very different qualities were tested in the same way throughout the same range or such parts of that range as were within their compass.

Too much space would be taken up if we were to give bere all the results obtained. It may be briefly said that the several voices agreed very fairly in respect of the partials composing the vowel at each pitch, that is to say, throughout the range 
TAble I. - Amplitudes of the Harmonic Constituentis of the Vowel Sound o Sing at Various Pitches by the same Voice.

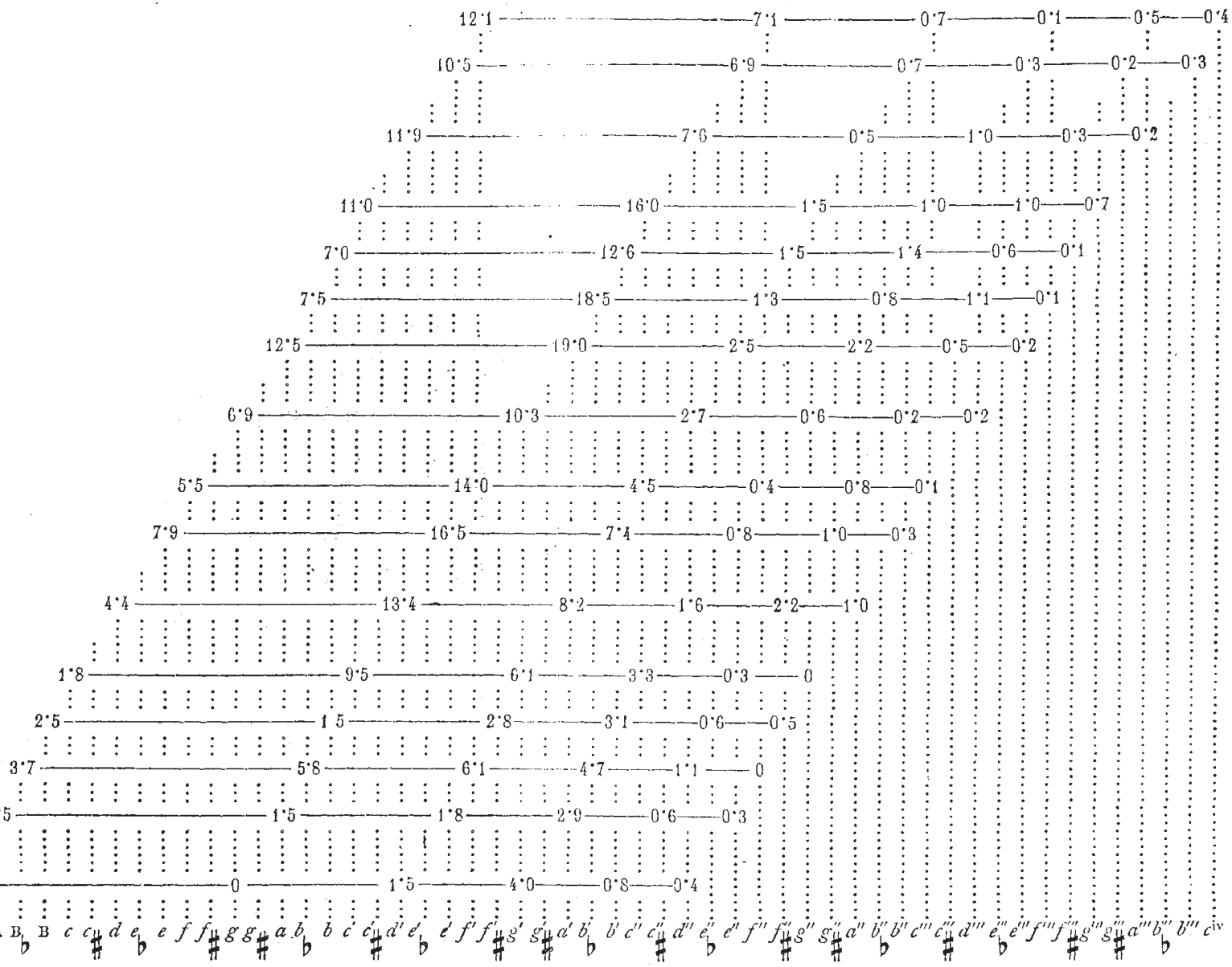

from $f^{\prime}$ to $g$ the first and second partials are the main com. different. Voice No. I was a fine, powerful, trained baritone. ponents; from $f$ to $d$ the third partial is prominent, and about $c$ the fourth partial becomes strong. At $G$, in one voice, the fifth partial was strong, whereas in the example now given it was weak.

When the several voices were compared in respect of the relative strength of the partials, it became clear that this relative strength might vary greatly without affecting the vowel quality much.

This is brought out by Table II., which contains the constituents of $\bar{o}$ as sung by five different voices on five different notes. The figures are proportional to the actual amplitudes of each harmonic constituent, and therefore not only show the relative value of each constituent in a given vowel, but also indicate (although only very roughly) the strength of the several voices on each note. Those constituents which are most considerable are printed in large type. Those printed in small type may perhaps be'regarded as accidental and not essential to the vowel sound.

On $e^{\prime}$ the vowel sound is composed of the two first partials, but with different voices these were present in proportions which varied from $\frac{100}{102}$ to $\frac{100}{34}$.

On $c^{\prime}$ the vowel sound was still composed almost wholly of the two first partials, and with different voices these were present in proportions which varied from $\frac{100}{145}$ to $\frac{100}{46}$. From this. it is evident that the vowel sound may vary very slightly as a vowel when the proportions of its constituents vary largely. No doubt it may be said that the vowels pronounced were different vowels, but it mist be remembered that each man was at least trying to sing the same vowel and was controlled by the same observers, who were satisfied that he did sing generically the same vowel.

On the other hand, the quality of the voices ? was extremely

No. 2 was a high-pitched voice with no notes below $f$, rather harsh, and unaccustomed to singing. No. 3 was the trained bass voice of a man of eighty. Nos. 4 and 5 were voices of average range and moderate power, with some musical training. No. 6 was a powerful bass. The differences in the proportions of the constituents appear to us therefore to indicate differences in the quality of the voices rather than differences in the vowel.

On $c^{\prime}$ the two first partials give a good $\bar{o}$, whether the second is one and a half times as big as the prime or the prime twice as big as the second.

The results on $a$ and $b$ do not differ much from those on $c^{\prime}$; when, however, we come to $g$, the table shows us that while two out of the five voices formed their $\bar{o}$ by producing two partials as in the case of the higher notes, three other voices introduced a considerable third partial. On descending one tone lower, to $f$, we find that all the voices agree in employing a strong third partial. This third partial is sometimes less than half the prime, but it is never so small as one-third, and in one case it is sensibly larger than the prime. It would also be observed that it was the voice No. 5, which had no sensible third on $g$ which gave the largest third on $f$. It should also be noted that the smallest third is due to voice No. 4, which was at the end of its range, and spoke or sang half a tone sharp.

As we descend below $f$ the third assumes more and more prominence; on $d$ voices $I$ and 5 gave the following series of partials :-

$$
\begin{array}{rrrrrrr} 
& \text { I. } & \text { II. } & \text { III. } & \text { IV. } & \text { V. } & \text { VI. } \\
I^{\circ} & 4^{\circ} 4 & \text { I } 3^{\circ} 4 & 8^{\circ} \cdot 2 & \text { I.6 } & 2^{\circ} \cdot 2 & \text { I.0 } \\
5^{\circ} & 3^{\circ} 3 & 7.2 & 5.6 & 0.5 & 0.7 & 0.2
\end{array}
$$

Table II. shows that by the time $B$ is reached the fourth partial has become very prominent. 
TABLE II.-Harmonic Constituents of $\bar{o}$ as Sung by different Voices.

\begin{tabular}{|c|c|c|c|c|c|c|c|}
\hline \multirow{2}{*}{ 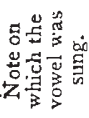 } & \multirow{2}{*}{$\begin{array}{l}\text { No. of } \\
\text { voice. }\end{array}$} & \multicolumn{6}{|c|}{ Amplitudes of the first six partial tones. } \\
\hline & & I. & II. & III. & IV. & v. & VI. \\
\hline$e^{\prime}$ & $\begin{array}{l}1 \\
2 \\
3 \\
4 \\
5\end{array}$ & $\begin{array}{r}10.5 \\
5.1 \\
5.3 \\
5.5 \\
5.2\end{array}$ & $\begin{array}{l}6.9 \\
3 \cdot 0 \\
1 \cdot 8 \\
3.4 \\
5.3\end{array}$ & $\begin{array}{l}0.7 \\
0.5 \\
0.3 \\
0.7 \\
0.5\end{array}$ & $\begin{array}{l}0 \cdot 2 \\
c^{\prime} 2 \\
0 \cdot 1 \\
0 \cdot 2 \\
0 \cdot 6\end{array}$ & $\begin{array}{l}0.3 \\
0.1 \\
0.2 \\
0.2\end{array}$ & $\begin{array}{l}0 \cdot 2 \\
0 \cdot 1 \\
0 \cdot 1 \\
0 \\
0.2\end{array}$ \\
\hline & {$\left[\begin{array}{r}\mathbf{I} \\
2 \\
3 \\
4 \\
5\end{array}\right.$} & $\begin{array}{r}11 \cdot 0 \\
{[4.5} \\
3.7 \\
5.4 \\
4.7\end{array}$ & $\begin{array}{r}16.0 \\
6.6 \\
3.0 \\
2.5 \\
4.1\end{array}$ & $\begin{array}{l}\mathrm{I} \cdot 5 \\
0.7 \\
0.1 \\
0 \\
0.5\end{array}$ & $\begin{array}{l}\mathrm{I} \cdot 0 \\
0.4 \\
0 \cdot 4 \\
0 \cdot 3 \\
0 \cdot 3 \\
0 \cdot 3\end{array}$ & $\begin{array}{l}0.1 \\
0.2 \\
0.3\end{array}$ & $\begin{array}{l}0.7 \\
0.2] \\
0.1 \\
0.1 \\
0.2\end{array}$ \\
\hline$s^{6}$ & $\begin{array}{l}\text { I } \\
2 \\
3 \\
4 \\
5\end{array}$ & $\begin{array}{l}6 \cdot 9 \\
2 \cdot 3 \\
4 \cdot 6 \\
3 \cdot 3 \\
3 \cdot 2\end{array}$ & $\begin{array}{r}10 \cdot 3 \\
5 \cdot 1 \\
2 \cdot 9 \\
4 \cdot 4 \\
5 \cdot 0\end{array}$ & $\begin{array}{l}2.7 \\
1.4 \\
0.2 \\
0.7 \\
0.3\end{array}$ & $\begin{array}{l}0.6 \\
0.3 \\
0 \cdot 2 \\
0 \cdot 2 \\
0.6\end{array}$ & $\begin{array}{l}0.2 \\
0.1 \\
0.1\end{array}$ & $\begin{array}{l}0 \cdot 2 \\
0 \cdot 2 \\
0 \cdot 1 \\
0 \cdot 2 \\
0 \cdot 2\end{array}$ \\
\hline$f$ & 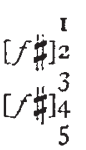 & $\begin{array}{r}5 \cdot 5 \\
{[1 \cdot 8} \\
2 \cdot 5 \\
{[2 \cdot 8} \\
2 \cdot 5\end{array}$ & $\begin{array}{r}14 \cdot 0 \\
5 \cdot 8 \\
3 \cdot 7 \\
6 \cdot 2 \\
2 \cdot 8\end{array}$ & $\begin{array}{l}4 \cdot 5 \\
1 \cdot 5 \\
1 \cdot 1 \\
1 \cdot 0 \\
3 \cdot 8\end{array}$ & $\begin{array}{l}0.4 \\
0.3 \\
0.3 \\
0.2 \\
0.4\end{array}$ & $\begin{array}{l}0.8 \\
0.1 \\
0.4 \\
0.3 \\
0.5\end{array}$ & $\begin{array}{l}0 \cdot 1 \\
0 \\
0.2 \\
0 \cdot 2] \\
0.1\end{array}$ \\
\hline$B\}$ & 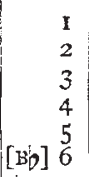 & $\begin{array}{r}2 \cdot 5 \\
2 \cdot 1 \\
0 \cdot 6 \\
{[1 \cdot 8}\end{array}$ & $\begin{array}{l}1 \cdot 4 \\
4 \cdot 6 \\
3 \cdot 8 \\
2 \cdot 2\end{array}$ & $\begin{array}{c}2 \cdot 8 \\
W \cdot a \\
2 \cdot 9 \\
W \\
2 \cdot 3 \\
3 \cdot 2\end{array}$ & $\begin{array}{c}3 \cdot 1 \\
2 \cdot 9 \cdot 8 \\
2 \cdot 8 \\
2 \cdot 5 \\
7 \cdot 5\end{array}$ & $\begin{array}{l}0.6 \\
1.0 \\
0.6 \\
0.9\end{array}$ & $\begin{array}{l}0.5 \\
0 \\
0.3 \\
0.2]\end{array}$ \\
\hline
\end{tabular}

Nora. - The analyses put within bracket; are a sem:toize different in pitch from the others in the gruup, and have their pitch marked at the side. They have been taken where there did not happen to be an example on th exact pitch wanted.

On $\mathrm{G}$ voice I gave the following series :-

$$
\begin{array}{lllllll}
\mathbf{I}^{\circ} & \mathbf{I}^{\circ} 3 & \mathrm{O} & \mathbf{I}^{\circ} 5 & 4^{\circ} \mathrm{O} & 0.8 & 0^{\circ} 4
\end{array}
$$

On $F$ another voice $($ No. 6) gave

$$
\begin{array}{lllllll}
6^{\circ} & 2.2 & 1.0 & I^{\circ} 5 & 0.8 & 3.4 & 0.1 .
\end{array}
$$

In this last example we see that the fifth partial was much greater than the prime.

For the sake of brevity we have only given a few cases. Our results contain the analyses of more than a hundred curves, from which we have given what we think fairly representative examples, Moreover, the curves analysed were in many instances chosen from numerous examples, so as to represent not one experiment, but several. We will now state the results arrived at in somewhat more general terms.

I. At those pitches commonly employed in conversation the sound $\bar{o}$ consists essentially of the first two partials of the note employed. The proportions between these partials may vary between $I: I^{\circ} 5$ and I : $0^{\circ} 5$; perhaps even more widely. When curves obtained by speaking were compared with those obtained by singing the proportions were much more nearly alike than could have been expected. The spoken $\bar{o}$ differed chiefly from the singing $\bar{o}$ by a continuous change of pitch, and also by running into an $\bar{u}$ towards the end of the utterance.

2. When $\bar{\sigma}$ is sung from $g$ downwards the third, fourth, and fifth partials appear in succession in such a way as to keep that which is the highest prominent partial not far from $b$, which is called by Helmholtz the characteristic tone of $\bar{o}$. Above $g$ the second and strongly reinforced partial lies in a region varying from three semitones below $b^{\prime} b$ to six semitones above it

3. Until we reach the lowest notes $G$ and $A$ all the partials between the prime and the highest prominent partial are more or less reinforced. Thus $\vec{o}$ successively consists of the first two partials, the first three partials, and the first four partials. On very low notes we have insufficient data for very positive conclusions, but the second partial seems to sink into insig. nificance as the fifth comes in.
4. The appearance of new partials as we descend the scale is in some cases and with some voices gradual; in other cases it is singularly abrupt.

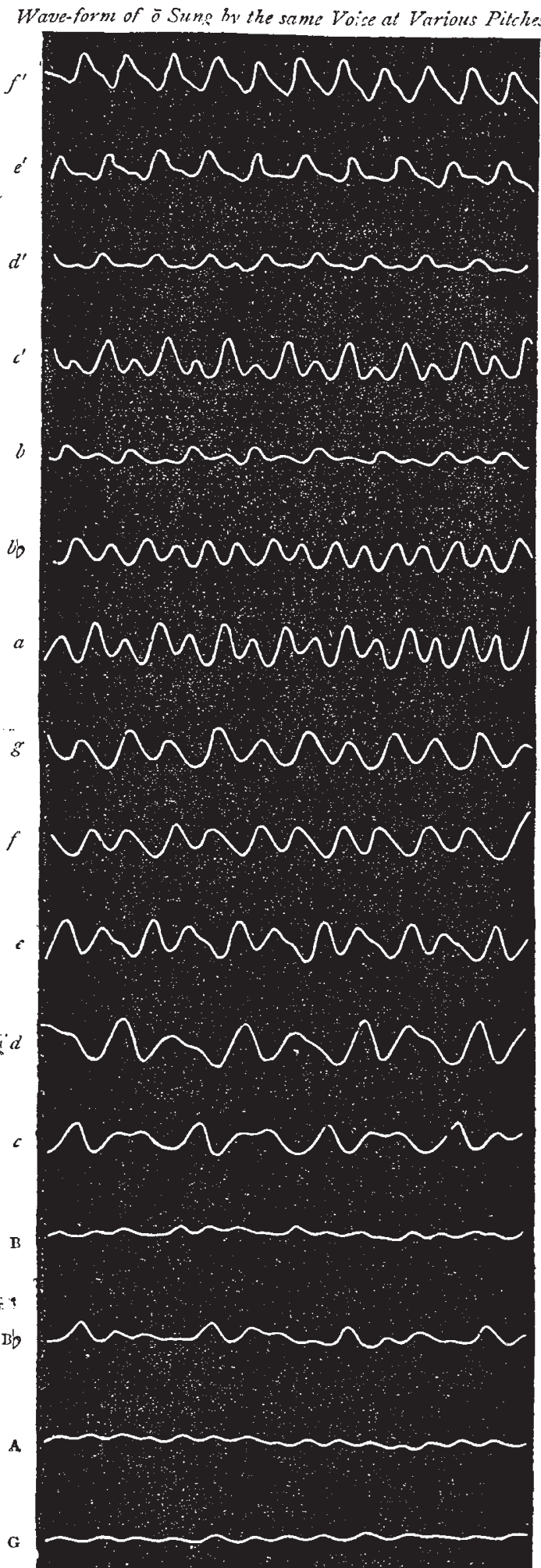

FIG. $x_{\text {. }}$

This is shown by Tables III, and IV., which give the actual 
amplitudes of the third and fourth partials for voices I, 3, and 5 at various pitches. The place where a somewhat sudden change happens is marked by a vertical bar.

TABLE III.-Third Partials.

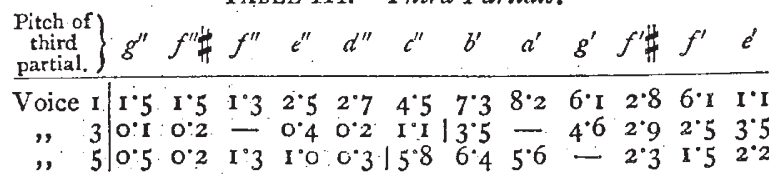

TADLE IV.-Fourth Partials.

\begin{tabular}{|c|c|c|c|c|c|c|c|c|c|c|c|}
\hline $\left.\begin{array}{l}\text { Pitch of } \\
\text { fourth } \\
\text { partial. }\end{array}\right\}$ & $c^{\prime \prime \prime} \quad b^{\prime \prime}$ & $b^{\prime} b$ & $a^{\prime \prime}$ & $g^{\prime \prime}$ & $f^{\prime \prime}$ & $e^{\prime \prime}$ & $d^{\prime \prime}$ & $c^{\prime \prime}$ & $b^{\prime}$ & $b^{\prime} b$ & $a^{\prime}$ \\
\hline $\begin{array}{cc}\text { Voice } & I \\
, & 3 \\
, & 5\end{array}$ & 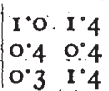 & $\frac{0.8}{0.7}$ & $\begin{array}{l}2 \cdot 2 \\
0.4 \\
0.8\end{array}$ & $\begin{array}{l}0.6 \\
0.2 \\
0.6\end{array}$ & $\begin{array}{l}0.4 \\
0.3 \\
1.3\end{array}$ & $\begin{array}{l}0.7 \\
0.5 \\
1.3\end{array}$ & $\frac{I .6}{0.5}$ & $\begin{array}{l}3 \cdot 3 \\
3 \cdot 5 \\
\end{array}$ & $\begin{array}{r}3.1 \\
2.8 \\
12.5\end{array}$ & $\begin{array}{l}4^{\circ} \cdot \\
3^{\circ} 6 \\
1 \cdot 5\end{array}$ & $\begin{array}{l}3 \% 9 \\
2 \cdot 1\end{array}$ \\
\hline
\end{tabular}

It will be seen that the third partial springs into prominence more suddenly with voices 3 and 5 than with voice $I$, but there is a rapid increase with voice $\mathbf{r}$, where the sudden change occurs with the other voices. This want of continuity suggests an adjustment or tuning of the mouth cavity, an idea which receives support from experiments on the sound $\vec{i}$, to be afterwards described.

Another very marked example of this sudden introduction of a new partial was given by voice 6 , a powerful bass.

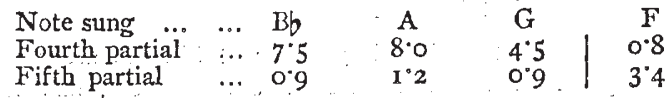

The apparent tuning of the mouth cavity required to produce the sudden introduction of a new partial might perhaps be described as the involuntary selection of a new $\vec{o}$ of different quality, but better adapted to be sung on the new note. We do not reject this mode of considering the phenomenon, but at the same time point out that there is a generic property common to the $\vec{o}$ s above and below the crltical notes which leads us to regard all the varieties as sensibly one and the same vowel sound. Our experiments do not so far show whether any tuning takes place in the upper part of the scale, where nothing but a prime and its octave are present.

5. Whenever a partial falls on $b^{\prime} b$ we find that it is specially prominent. This fact was ascertained by Helmholtz; and the confirmation of his experiments by a completely different method is very satisfactory, both as showing that the letter $\bar{o}$, as pronounced by the English and German singers, did not differ sensibly, and as tending to justify our confidence in the method of investigation which we have followed. In that part of the scale where the vowel consists simply of the prime and its octave, the second partial, when it falls on $b^{\prime} b$, is usually a maximum, both absolutely and relatively to the prime. This result was to be expected from the experiments of Helmboltz and Donders.

6. The upper partials are often larger in amplitude than the prime.

The second partial was occasionally a little more than double the prime; the third partial in low notes was sometimes four times as great as the prime. The fourth partial was in one case eight times as large as the prime and the fifth partial in our single example on $F$ was. one and a half times the prime.

We defer drawing any conclusions from these results until we have described the analogous phenomena observed for the vowel sound $\bar{i}$.

$$
\text { J. A. EWING }
$$

\section{NOTES}

PROF. F. V. HAYDEN has recently been elected Foreign Member of the Royal Acalemy of Sciences, Rome. This is one of the oldest scientific societies in the world, and the number of foreign members in the department of the natural sciences is only thirty-seven. The University of Rochester (U.S.) at its annual commencement on the 3 rd instant, conferred on Dr. Hayden the honorary degree of Doctor of Laws. In his letter communi. cating its action, the president, Rev. Dr. M. B. Anderson, says :- " The Trustees and Faculty of the University desired to recognise by this action your great services to science through your personal attainments, as well as the almost unparalleled energy and success which have characterised your explorations in regions hitherto unknown to the geologist as such. They did not hope to add in the slightest degree to your well-earned reputation, but they desired to express their appreciation of the honour you have done our country and the state and city of your early residence, by those great labours which have linked your name with geological science for all coming time. The friendship of many years has made my official connection with this public act a source of the most sincere pleasure."

THE Netherlands Zoological Society held its annual summer meeting at Harlingen on July I4 last. The chairman of the Committee for the Zoological Station, Dr. Hubrecht, $;$ gave a short statement showing how the prospects of the young institution had con siderably improved during the past year, how an annual income of about $150 \%$. had been obtained, which had permitted an extension of the wooden building, described and figured in NATURE, as well as the application of a new heated air motor (system Rennes, Utrecht) for oxygenising the sea-water in the aquaria by a constant stream of atmospheric air. The transportable Zoological Station has been erected during the summer months of 1878 , on the Island of Terschelling, between the Zuyder and North Seas, and several members of the Society are there now, for the greater part occtipied in the study of the invertebrate fauna of the Dutch coast. These investigations are being considerably facilitated by the great liberality of the Marine Minister, who has put a vessel with a mate and three sailors at the entire disposal of the Committee for the next six or eight weeks. As has hitherto been done, it is expected that at the end of the season a circumstantial report will be issued by the Committee, in which the results of this year's campaigning will be duly recorded.

THE death is announced of Dr. Thomas Oldham, who was, from its origination in 1850 till 1876 , at the lhead of the Geological Survey of India. It was under his direction that the official geological survey was commenced, first under the Hon. East India Company and afterwards as part of the Government public service; and until his retirement, from ill-health, he had the control of the issue of the official geological maps, as, portion by portion, the work was completed, and the issue of the memoirs explanatory of the maps. In I86r, eleven years after the survey was commenced, he originated the publication of the folio-sized "Palæontologia Indica," which consisted of plates, with descriptive letter-press, illustrating the fossils of the country, and the work has progressed steadily in fasciculi as an official publication printed by command of the GovernorGeneral of India. Dr. Oldham was born in Dublin in May, 1816, and entered at Trinity College, Dublin, at the age of sixteen. After taking his B.A., he studied in 1837.38 at the engineering school of Edinburgh, and attended Jameson's lectures on geology and mineralogy. Returning to Ireland in 1839 , he: became chief geological assistant to Major-General Portlock, then at the head of the survey of Ireland, and he helped in the preparation of the well-known report on Londonderry, Tyrone, \&c., published in 1843 . After being for a while curator and assist. ant-secretary of the Geological Society of Dublin, he held for a year the professorship of engineering, and in 1845 succeeded the late Prof. John Phillips as Professor of Geology. He was then appointed local director of the geological survey of Ireland, and the Geological Society of Dublin elected him its president. After the various experiences thus gained, in 1850 he was appointed to organise the geological survey of India. There were many unexpected difficulties to. 